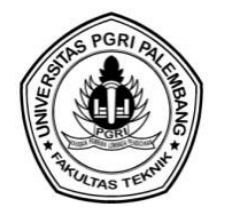

\title{
PENGARUH PENAMBAHAN BUBUK BATUBARA SEBAGAI FILLER PADA CAMPURAN ASPAL AC WC
}

\author{
Tri Cahyono, Herri Purwanto*, Agus Setiobudi, M. Firdaus
}

Program Studi Teknik Sipil, Fakultas Teknik, Universitas PGRI Palembang

*Corresponding Author, Email : irwanto1969@gmail.com

\begin{abstract}
ABSTRAK
Batubara merupakan salah satu sumber energi alam yang dibutuhkan dalam kehidupan dan salah satu sumber energi di dunia, berwarna coklat sampai hitam, yang mengalami proses fisika dan kimia serta kaya kandungan karbon. Aspal beton adalah suatu jenis perkerasan konstruksi jalan yang terdiri dari campuran aspal dan agregat, baik dengan bahan tambah maupun atau tanpa bahan tambah. Tujuan dilakukan penelitian ini adalah untuk mengetahui seberapa besar pengaruh bubuk batubara sebagai bahan tambah filler pada campuran aspal AC WC dengan variasi campuran 0\%, 1\%, 2\%, 3\%. Dari hasil penelitian campuran aspal AC WC yang digunakan sudah sesuai standar Spesifikasi Umum 2018 Revisi 2 Dinas PU Bina Marga yaitu pada kondisi kadar aspal 5,7\%, dengan nilai density 2,246 gr/cc, nilai VMA 16,92\%, nilai VFB 73,14\%, nilai VIM 4,54\%, nilai stabilitas $1169 \mathrm{~kg}$, nilai flow 3,7 mm dan nilai marshall quotient 324,7 $\mathrm{kg} / \mathrm{mm}$. Dari pengujian setelah penambahan variasi filler 0\%, 1\%, 2\%, 3\%., didapat hasil nilai VMA maksimal sebesar 75,1\% pada variasi 3\%, nilai VIM maksimal sebesar 5,48\% pada variasi $0 \%$, nilai VFB maksimal sebesar 16,26\% pada variasi $2 \%$, nilai stabilitas maksimal sebesar $1828 \mathrm{~kg}$ pada variasi 3\%, nilai flow maksimal sebesar 3,53 mm pada variasi $0 \%$, dan nilai marshall quotient maksimal sebesar $600 \mathrm{~kg} / \mathrm{mm}$ pada campuran 3\%. Dan semua penambahan bubuk batubara sebagai filler dengan variasa 1\%, 2\% dan $3 \%$ sebagai campuran aspal AC WC memenuhi syarat spesifikasi umum revisi 2 tahun 2018 revisi 2 Dinas Pekerjaan Umum Bina Marga
\end{abstract}

Kata Kunci : Bubuk Batu Bara; Filler; Marshall Test

\begin{abstract}
Coal is one of the natural energy sources needed in life and one of the energy sources in the world, brown to black in color, which undergoes physical and chemical processes and is rich in carbon content. Asphalt concrete is a type of road construction pavement consisting of a mixture of asphalt and aggregate, either with or without added materials. The purpose of this study was to determine how much influence coal powder as a filler added to the AC WC asphalt mixture with a mixture variation of $0 \%, 1 \%, 2 \%, 3 \%$. From the results of the research, the AC-WC asphalt mixture used was in accordance with the General Specifications 2018 Revision 2 of the Public Works Department of Highways, namely the condition of the asphalt content of $5.7 \%$, with a density value of $2.246 \mathrm{gr} / \mathrm{cc}$, a VMA value of $16.92 \%$, a VFB value of 73, 14\%, 4.54\% VIM value, stability value $1169 \mathrm{~kg}$, flow value $3.7 \mathrm{~mm}$ and marshall quotient value 324.7 $\mathrm{kg} / \mathrm{mm}$. From the test after adding filler variations of $0 \%, 1 \%, 2 \%, 3 \%$, the maximum VMA value is $75.1 \%$ at $3 \%$ variation, maximum VIM value is $5.48 \%$ at $0 \%$ variation, maximum VFB value of $16.26 \%$ in the $2 \%$ variation, the maximum stability value of $1828 \mathrm{~kg}$ at the $3 \%$ variation, the maximum flow value of $3.53 \mathrm{~mm}$ at the $0 \%$ variation, and the maximum marshall quotient value of $600 \mathrm{~kg} / \mathrm{mm}$ at the $3 \%$ mixture. And all additions of coal powder as filler with variations of 1\%, 2\% and 3\% as a mixture of asphalt AC WC meet the general specifications revision 2 of 2018 revision 2 of the Public Works Department of Highways
\end{abstract}

Keywords : Coal Powder; Filler; Marshall Test

\section{PENDAHULUAN}

Aspal beton telah lama dikenal sebagai bahan konstruksi jalan dan banyak digunakan dalam pembangunan konstuksi jalan. Menurut Sukirman (dalam Fahmi 2021), aspal beton 
adalah suatu jenis perkerasan konstruksi jalan yang terdiri dari campuran aspal dan agregat, baik dengan bahan tambah maupun atau tanpa bahan tambah. Di mana material pembentuknya dicampur pada suhu tertentu berdasarkan jenis aspal yang akan digunakan. Beton aspal merupakan campuran dari agregat bergradasi menerus dan bahan aspal komponen ditambahankan ke dalam campuran untuk meminimalisir dasar aspal sehingga mengatasi kelemahan aspal. Batubara merupakan salah satu sumber energi alam yang dibutuhkan dalam kehidupan dan salah satu sumber energi di dunia. Batubara (Sukandarrumidi 1995) merupakan batuan sedimen (padatan) yang dapat terbakar, berasal dari tumbuhan, serta berwarna coklat sampai hitam, yang mengalami proses fisika dan kimia serta kaya kandungan karbon. Menurut Elliot (dalam Arif 2014) batubara merupakan batuan sedimen yang secara kimia dan fisika adalah heterogen yang mengandung unsur-unsur karbon, hidrogen, dan oksigen sebagai komponen unsur utama dan belerang serta nitrogen sebagai unsur tambahan, serta zat lain, berupa senyawa anorganik pembentuk ash (debu) yang tersebar sebagai partikel zat mineral yang terpisah di seluruh senyawa batubara.

Menurut Sugeha et al (2018), aspal beton (AC) atau biasa dikenal dengan laston (lapisan aspal beton) adalah lapisan permukaan yang terdiri dari laston sebagai lapisan tahan aus. Di mana laston terbuat dari agregat kelas kasar yang terdiri dari pasir dan campuran aspal keras, kemudian diaspal dan dipadatkan dalam keadaan panas suhu tertentu. Menurut Iqbal et al (2020) agregat adalah partikel yang berupa butiran yang digunakan sebagai bahan untuk membuat beton dan lapisan pondasi jalan, dimana dalam struktur perkerasan jalan, agregat merupakan komponen utama sebesar yaitu 90\%-95\% berat atau 75\%-85\% volume. Dapat dikatakan kualitas perkerasan suatu konstruksi jalan sangat tergantung dari hasil campuran agregat (Tenriajeng 2002). Menurut Sukirman (1992), filler adalah kumpulan dari agregat halus yang lolos saringan nomor 200, dan berfungsi untuk mengisi rongga-rongga partikel agregat kasar sehingga meningkatkan kerapatan dan stabilitas dari masa tersebut. Lapisan perkerasan merupakan kombinasi dari aspal, agregat kasar, agregat halus, dan (filler), di mana filler adalah lapisan pengisi yang berfungsi untuk mengisi rongga-rongga udara pada perkerasan jalan, yang berupa semen, abu batu, dan abu kapur (Anggraini, et al 2020). Fahmi (2021) dalam penelitiannya, menggunakan limbah abu terbang pada batu bara (fly ash) sebagai campuran aspal beton (laston) AC WC dengan kadar variasi limbah abu terbang batubara (fly ash) 0\%, 25\%, dan $50 \%$ dan variasi aspal 4,5\%, 5\%, 5,5\%, 6, 6,5\%, di mana penelitian yang dilakukan dengan menggunakan metode marshall test. Dari hasil penelitian, pengaruh karakteristik marshall yang terjadi pada subtitusi kadar fly ash $25 \%$ pada laston AC WC didapat nilai VIM (Void In Mix / volume rongga dalam campuran) sebesar 3,97\% (memenuhi standar 3,5\% - 5,5\%), nilai VMA (Void In Mineral Agreggate / volume rongga diantara mineral) sebesar 23,37\% (memenuhi standar minimal 15\%), nilai VFA (Void Filled With Asphalt / volume rongga terisi aspal) $83,40 \%$ (memenuhi standar minimal $65 \%$ ), nilai marshall quotient sebesar $130,39 \mathrm{~kg} / \mathrm{mm}$ (tidak memenuhi standar minimal $250 \mathrm{~kg} / \mathrm{mm}$ ) dan nilai stabilitas sebesar 595,38 kg (tidak memenuhi standar minimal $800 \mathrm{~kg}$ ). Sedangkan pengaruh karakteristik marshall yang terjadi pada subtitusi kadar fly ash $50 \%$ pada laston AC WC didapat nilai VIM sebesar 3,79\% (memenuhi standar), nilai VMA sebesar $21,17 \%$ (memenuhi standar), nilai VFA $82,11 \%$ (memenuhi standar), nilai marshall 
quotient sebesar 122,29 $\mathrm{kg} / \mathrm{mm}$ (tidak memenuhi standar) dan nilai stabilitas sebesar $561,08 \mathrm{~kg}$ (tidak memenuhi standar). Menurut penelitian Sa'dillah \& Leliana (2020) yang menyimpulkan bahwa hasil penelitian karakteristik penambahan bahan pengisi abu terbang batu bara pada lapisan aspal AC WC dengan variasi abu batu bara 5\%, 6\%, 7\%, $8 \%, 9 \%$, mendapatkan nilai stabilitas tertinggi yaitu pada kandungan $7 \%(1472,51 \mathrm{~kg})$, dan semakin ditambah filler maka nilai stabilitas akan terus meningkat, demikian juga dengan nilai VIM dan VMA akan ikut meningkat. Dimana semakin ditambah kandungan filler abu terbang batu bara, menyebabkan rongga-rongga campuran beton aspal menjadi lebih kecil dan lebih kedap air. Dan hal ini menunjukkan bahwa fly ash berperan dalam mengisi celah agregat dan dan menjadi pengunci campran aspal beton. Tahir (dalam Syahrul 2021), menyatakan bahwa penambahan campuran filler abu terbang batu bara kedalam campuran beton aspal akan semakin kaku dengan nilai MQ (Marshall Quotient) yang cenderung meningkat seiring dengan bertambahnya variasi kadar filler abu terbang batu bara kedalam campuran. Stabilitas campuran yang menggunakan filler abu terbang batu bara (fly $a s h$ ) cenderung mengalami kenaikan sampai pada batas optimum kemudian mengalami penurunan, di mana stabilitas tertinggi tercapai pada kadar aspal $6 \%$ dengan kadar filler optimum berkisar 6\% - 7\%. Menurut Abdullah, et al (2017), dengan penelitiannya yang mengganti filler batu bara dengan dengan abu batubara, dan dari hasil penelitian yang dilakukan didapat nilai Flow pada campuran aspal mengalami peningkatan pada kadar 25\% abu batu bara dengan nilai sebesar 3,30 mm dan kemudian meningkat sebesar 0,91\% menjadi 3,33 $\mathrm{mm}$ pada kadar 50\% abu batu bara, kemudian terus meningkat seiring bertambahnya kadar abu batu bara dalam campuran. Hal ini disebabkan nilai VIM (Void In Mix / volume rongga dalam campuran) dapat menerima kadar abu batu bara dan rongga dalam campuran bertambah licin. Sedangkan nilai stabilitas pada campuran aspal mengalami penurunan dimulai pada kadar $25 \%$ abu batu bara sebesar $1431 \mathrm{~kg}$, kemudian menurun sebesar 70,79\% pada kadar 50\% abu batu bara sebesar 1418 kg. Nilai stabilitas mengalami penurunan seiring bertambahnya kadar abu batu bara dalam campuran. Hal ini disebabkan oleh menurunnya penggunaan butiran abu batu yang mengakibatkan film aspal menjadi tebal, sehingga fungsi aspal sebagai pengikat akan berubah.

Tujuan dilakukan penelitian ini adalah untuk mengetahui seberapa besar pengaruh bubuk batu bara sebagai bahan tambah filler pada campuran aspal AC WC dengan variasi campuran $0 \%, 1 \%, 2 \%, 3 \%$.

\section{METODE PENELITIAN}

Penelitian ini dilakukan di laboratorium AMP PT HKA MUSI 2 Palembang, dengan melakuka pengujian campuran aspal AC WC dengan Marshall Test menggunakan variasi bubuk batubara $1 \%, 2 \%, 3 \%$ sebagai filler. Material yang digunakan berupa campuran aspal AC WC dengan filler serbuk batubara sebagai bahan tambah, yaitu : (1) Agregat kasar berukuran 1/2 dan 1/1 dari stone crusher PT. HKA Bojonegara Banten; (2) Agregat halus berupa abu batu; (3) Filler dari batubara yang dihaluskan; (4) Aspal curah (bitumen) penetrasi Singapore shell 60/70 dari PT Karya Mandiri Nusantara Dumai (KMN). Pengujian dilakukan untuk mengetahui nilai Density, VMA (Vold In Mixture Agregat), 
VFB (Volt Fith Bitumen), VIM (Vold In Mix), Stability, Kelelehan (Flow) dan Marshall Quotient terhadap campuran aspal beton AC WC dengan penambahan kadar filler abu batu bara sebesar $0 \%, 1 \%, 2 \%$ dan $3 \%$

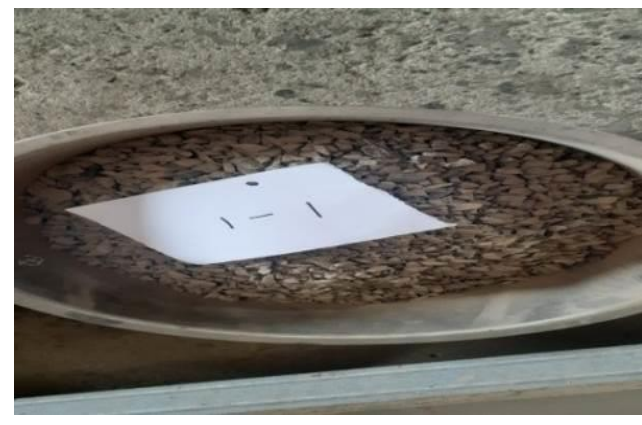

(a) Agegat $1 / 1$

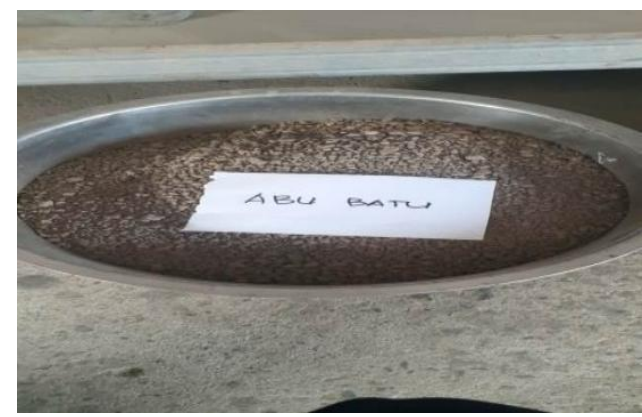

(c) Abu Batu

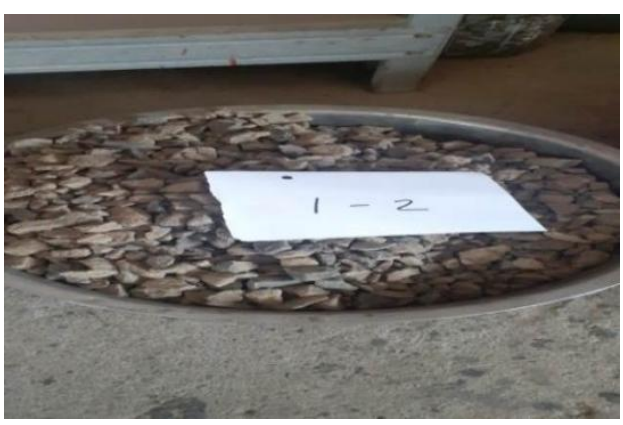

(b) Agregat 1/2

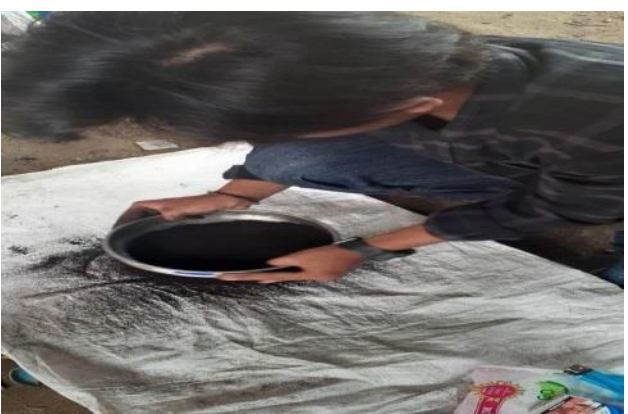

(d) Filler

Gambar 1. Material Yang Digunakan

\section{HASIL DAN PEMBAHASAN}

Dari hasil penelitian dengan Marshall Test pada campuran aspal AC WC normal didapat kadar aspal optimum seperti tabel berikut :

Tabel 1. Hasil pemeriksaan marshall test campuran aspal AC WC normal

\begin{tabular}{clccccc}
\hline \multirow{2}{*}{ No } & \multicolumn{1}{c}{ AC WC } & 5,0 & 5,5 & 5,7 & 6,0 & \multirow{2}{*}{ Spesifikasi } \\
\cline { 3 - 6 } & & 2,274 & 2,279 & 2,246 & 2,284 & - \\
2 & Density (gr/cc) & 14,94 & 15,33 & 16,92 & 15,48 & Min. 15 \\
3 & VFB (\%) & 63,54 & 68,29 & 73,14 & 74,6 & Min. 65 \\
4 & VIM (\%) & 5,45 & 4,71 & 4,54 & 3,93 & $3,0-5,0$ \\
5 & Stabilisasi (kg) & 1144,1 & 1267,0 & 1169,0 & 1181,9 & Min 1200 \\
6 & Flow (mm) & 3,35 & 3,45 & 3,7 & 3,6 & $2,0-4,0$ \\
7 & Marshall Quotient (kg/mm) & 341,6 & 367,5 & 324,7 & 328,3 & Min 250 \\
\hline
\end{tabular}

Dari tabel diatas, campuran aspal AC WC yang digunakan sudah sesuai standar spesifikasi yang dipersyaratkan dari Spesifikasi Umum 2018 Revisi 2 Dinas PU Bina Marga yaitu pada kondisi kadar aspal 5,7\%, dengan nilai density 2,246 gr/cc, nilai VMA 16,92\%, nilai VFB 73,14\%, nilai VIM 4,54\%, nilai stabilitas $1169 \mathrm{~kg}$, nilai flow $3,7 \mathrm{~mm}$ dan nilai marshall quotient $324,7 \mathrm{~kg} / \mathrm{mm}$, yang ditunjukkan tabel dan gambar berikut. 
Tabel 2. Hasil pemeriksaan marshall test campuran aspal AC WC dengan penambahan variasi filler bubuk batubara

\begin{tabular}{cccccccc}
\hline No & $\begin{array}{c}\text { Variasi } \\
\text { Filler }\end{array}$ & $\begin{array}{c}\text { VIM } \\
(\%)\end{array}$ & $\begin{array}{c}\text { VMA } \\
(\%)\end{array}$ & $\begin{array}{c}\text { VFB } \\
(\%)\end{array}$ & $\begin{array}{c}\text { Stabilitas } \\
(\mathrm{kg})\end{array}$ & $\begin{array}{c}\text { Flow } \\
(\mathrm{mm})\end{array}$ & $\begin{array}{c}\text { Marshall } \\
\text { Quotient } \\
(\mathrm{kg} / \mathrm{mm})\end{array}$ \\
\hline 1 & $0 \%$ & 5,48 & 16,19 & 66,18 & 1658 & 3,5 & 412 \\
2 & $1 \%$ & 5,01 & 15,71 & 68,10 & 1765 & 2,83 & 598 \\
3 & $2 \%$ & 4,37 & 16,26 & 73,13 & 1786 & 3,43 & 506 \\
4 & $3 \%$ & 3,96 & 15,91 & 75,10 & 1828 & 3,03 & 600 \\
5 & Spesifikasi & $3,0-5,0$ & Min. 15 & Min. 65 & Min & $2,0-4,0$ & Min 250 \\
& & & & & 1200 & & \\
\hline
\end{tabular}

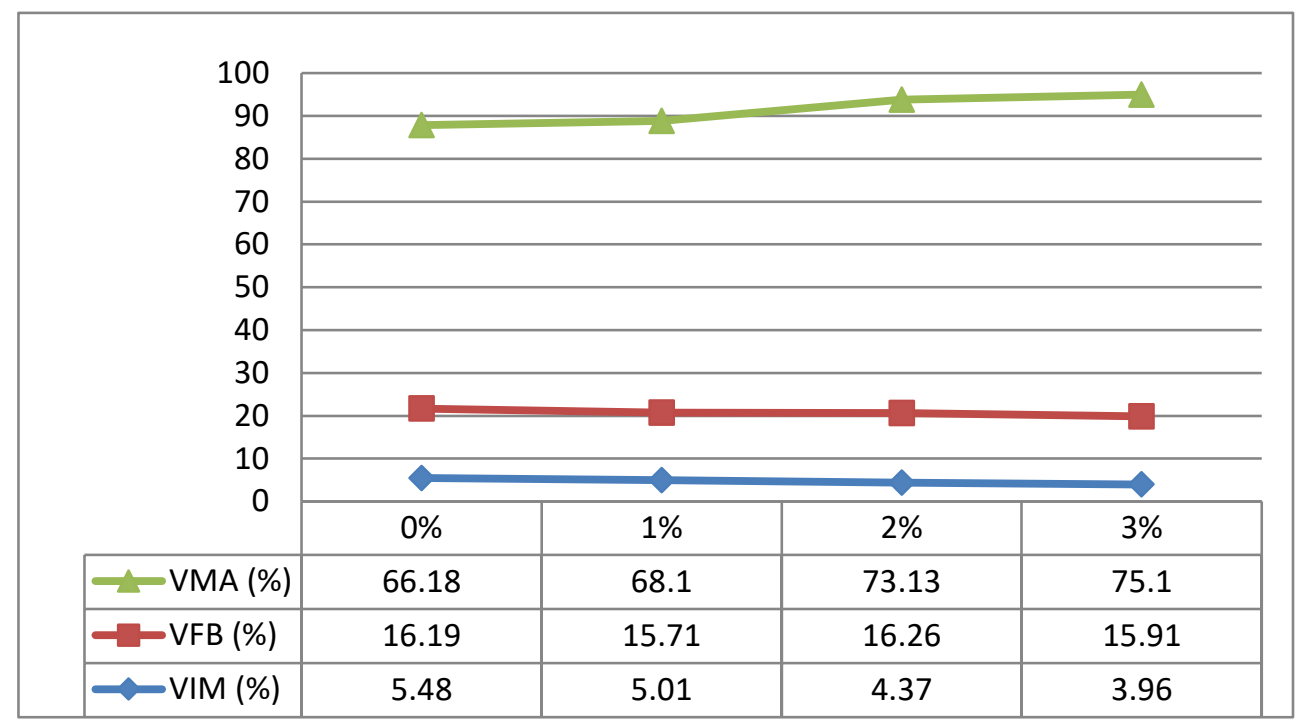

Gambar 2. Grafik Nilai VIM, VMA dan VFB Dengan Variasi Campuran Filler

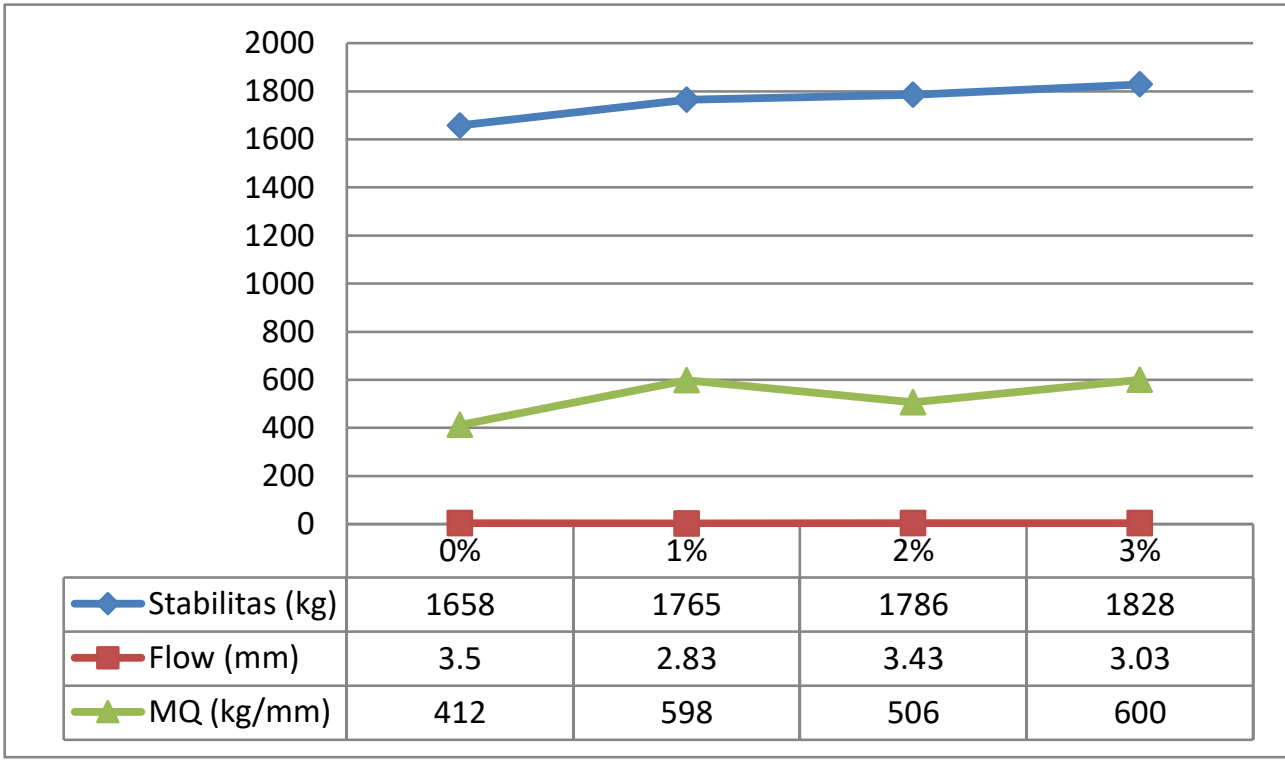

Gambar 3. Grafik Nilai Stabilitas, Flow dan MQ Dengan Variasi Campuran Filler 
Pada gambar 2 dan 3 diatas pada kadar aspal 5,7\%, nilai VMA cenderung semakin meningkat dengan nilai maksimal sebesar $75,1 \%$ pada variasi $3 \%$, nilai VIM cenderung semakin menurun dengan nilai maksimal sebesar $5,48 \%$ pada variasi $0 \%$, dan nilai VFB bersifat fluktuatif dengan nilai maksimal sebesar $16,26 \%$ pada variasi $2 \%$. Sedangkan stabilitas campuran cenderung menaik dengan nilai maksimal sebesar $1828 \mathrm{~kg}$ pada variasi $3 \%$, nilai flow cenderung meningkat tetapi hanya maksimal sebesar 3,53 mm pada variasi $0 \%$, dan nilai marshall quotient fluktuatif dan nilai maksimal sebesar $600 \mathrm{~kg} / \mathrm{mm}$ terjadi pada campuran $3 \%$

\section{KESIMPULAN}

Dari hasil penelitian penambahan bubuk batubara sebagai pengisi (filler) pada campuran aspal AC WC disimpulkan sebagai berikut :

1. Kadar aspalAC WC yang digunakan dengan kadar 5,7\% dengan nilai density 2,246 gr/cc, nilai VMA 16,92\%, nilai VFB 73,14\%, nilai VIM 4,54\%, nilai stabilitas 1169 $\mathrm{kg}$, nilai flow 3,7 mm dan nilai marshall quotient $324,7 \mathrm{~kg} / \mathrm{mm}$

2. Nilai VMA maksimal sebesar $75,1 \%$ pada variasi $3 \%$, nilai VIM maksimal sebesar $5,48 \%$ pada variasi $0 \%$, nilai VFB maksimal sebesar $16,26 \%$ pada variasi $2 \%$, nilai stabilitas maksimal sebesar $1828 \mathrm{~kg}$ pada variasi 3\%, nilai flow maksimal sebesar 3,53 $\mathrm{mm}$ pada variasi $0 \%$, dan nilai marshall quotient maksimal sebesar $600 \mathrm{~kg} / \mathrm{mm}$ pada campuran $3 \%$

3. Pengujian kuat tekan Marshall Test dengan variasi 1\%, 2\% dan 3\% sebagai campuran aspal AC WC, dengan hasil memenuhi syarat spesifikasi umum revisi 2 tahun 2018 revisi 2 Dinas Pekerjaan Umum Bina Marga

\section{DAFTAR PUSTAKA}

Abdullah, Z. Z., Wesli, W., \& Akbar, S. J. (2017). Penggunaan Abu Batu Bara Sebagai Filler Pada Campuran Aspal Beton AC-BC. TERAS JURNAL-Jurnal Teknik Sipil, 6(2), 121-130.

Andi Tenrisukki Tenriajeng 2002, Rekayasa Jalan Raya, Gunadarma, Jakarta, Indonesia.

Anggraini, Y., Malik, A., \& Sebayang, M. (2020). Analisa Kinerja Campuran AC-WC dengan Pemanfaatan Kombinasi Limbah Abu Bata dan Abu Serbuk Kayu Sebagai Filler. Sainstek (e-Journal), 8(2), 70-80.

Arif, I. I. (2014). Batubara Indonesia. Gramedia Pustaka Utama.

Fahmi, A.K.A. (2021). Karkteristik Campuran Beton Aspal (AC-WC) Dengan Menggunakan Variasi Kadar Filler Limbah Abu Terbang Batubara. Jurnal Online SKRIPSI Manajemen Rekayasa Konstruksi Politeknik Negeri Malang, 2(1), 51-57.

Iqbal, M., Amiwarti, A., \& Setiobudi, A. (2020). Analisis Penambahan Limbah Las Karbit Sebagai Filler Campuran Aspal AC WC. Jurnal Deformasi, 5(1), 43-47 
Sa'dillah, M., \& Leliana, A. (2020, October). Jurnal Prosiding Sentikuin vol 3 AGUSTUS 2020 Karakteristik Aspal Beton Lapis Aus (AC-WC) Dengan Penambahan Bahan Pengisi Abu Terbang Batubara. In Prosiding Seminar Nasional Teknologi Industri, Lingkungan, dan Infrastruktur (SENTIKUIN) (Vol. 3, p. D7). Fakultas Teknik Universitas Tribhuwana Tunggadewi.

Silvia Sukirman, Perkerasan Lentur Jalan Raya, Penerbit NOVA Tahun 1999.

Sugeha, A. L. R., Sulandari, E., \& Suyono, R. S. Pemanfaatan Limbah Abu Batu bara sebagai filler pada campuran Laston. Jurnal Mahasiswa Teknik Sipil Universitas Tanjungpura, 5(3).

Sukandarrumidi, 1995. Batubara dan Gambut, Gajahmadha University, Press Yogyakarta

Syahrul, H. P. (2021). Studi Penggunaan Limbah Abu Batu bara (fly ash) Sebagai Pengganti Filler Pada Campuran AC-WC Terhadap Karakteristik Uji Marshall (Doctoral dissertation, Universitas_Muhammadiyah_Mataram). 